\title{
Electronic theses: the turning point
}

\section{Susan Copeland, Andrew Penman and Richard Milne}

The Robert Gordon University, Aberdeen, UK

\begin{abstract}
Purpose: To describe the key findings of the UK JISC-funded Electronic Theses project that was led by The Robert Gordon University, as well as the results of associated projects that formed part of the JISC- funded 'FAIR' Programme, and the way in which the recommendations will be taken forward.
\end{abstract}

Design/methodology/approach: The research involved: an assessment of existing best practice relating to the production, management and use of e-theses; the use of questionnaires to obtain feedback from potential users; the identification and testing of potentially useful software; consideration of the elements required in a metadata core set, and discussions with representative bodies to ensure that the model recommended for use in the UK had support from the key stakeholders.

Findings: Information is provided about the value of the NDLTD Web site, the suitability of DSpace and EPrints software for institutional e-theses repositories, and the recommended infrastructure for the operation of an e-theses service at national level. Details are included about the agreed metadata core set for UK e-theses, and advice is provided about administrative, legal and cultural issues.

Practical Implications: The JISC-funded EThOS project is taking forward many of the recommendations from the Electronic Theses project.

Originality/value: The research results described in this paper will be of use to institutions which are aiming to establish their own e-theses collections. The details provided about the UK approach towards the management of e-theses may be of use in countries which have not yet made their theses available in electronic format.

\section{Introduction}

For over a decade there has been debate amongst academics and librarians about the benefits, and difficulties, of maintaining a collection of theses that have been submitted in electronic format. In the UK, initial investigation in this area was instigated by members of the University Theses Online Group (UTOG) in the mid-1990s. A survey undertaken by the 
University of Edinburgh, on behalf of UTOG (Roberts, 1997) confirmed that there was a significant level of support from postgraduate students for the idea of e-theses in principle. However, in the absence of adequate resources to undertake large scale developmental work, little practical progress was achieved for several years.

In 2002 the situation changed significantly in the UK when the Joint Information Systems Committee (JISC) announced that it would provide funding for three projects to pursue research and development work associated with the collection and management of e-theses as part of the Focus on Access to Institutional Resources (FAIR) Programme (http://www.jisc.ac.uk/index.cfm?name=programme fair). One of these, the Electronic Theses project, involved a consortium of five institutions. It was led by The Robert Gordon University in Aberdeen, Scotland and received input from representatives from the University of Aberdeen, Cranfield University, the University of London Library, and the British Library. This project aimed to evaluate a wide range of existing practice and methods of e-theses production, management and use against a set of criteria in order to produce recommended models designed for use within the UK information environment. Throughout the duration of the project, members of the Electronic Theses team liaised closely with their counterparts involved in the other two funded projects at the University of Edinburgh (who were working on the Theses Alive! project (http://www.thesesalive.ac.uk)) and at the University of Glasgow ( who were working on the Daedalus project (http://www.lib.gla.ac.uk/daedalus/)).

All three of the FAIR e-theses projects considered ICT requirements, legal and administrative concerns, and cultural and advocacy issues. The emphasis and approach towards investigating these matters varied between the projects, but the findings were broadly similar. In particular, there was a common view with regard to the selection of preferred software for e-theses repositories, and agreement was reached on the identification of a core-set of metadata.

Representatives from the three projects participated in two major dissemination events which took place in London in 2004 to ensure that the proposals and recommendations they promoted to the wider Higher Education (HE) community in the UK were co-ordinated. The first seminar, which was held at the University of London Library (ULL) in January 2004, was fully booked within days of being advertised (http://www.rgu.ac.uk/library/uk-theses.htm). The event was intended to allow the project teams to promote the results they had achieved by this stage and to receive feedback on the proposals they intended to publicise as recommendations at the end of the year. The comments of those attending the event were very positive and revealed a strong desire for practical advice which they could use in their efforts to establish their own e-theses repositories and to encourage students to submit content in the appropriate format. The level of attendance at the second seminar, which was held in a large venue at the British Library in September 2004 
(http://www.rgu.ac.uk/library/about/events.html), exceeded that at the former event and the recommendations made by the representatives from the project teams were well received. Efforts are now being made to ensure that future work relating to e-theses in individual institutions, and in terms of the creation of a national infrastructure, take into account the findings of the earlier projects. This paper highlights the key results of the JISC-funded etheses projects, and details the work of the Electronic Theses project in particular, in order to demonstrate the range of issues that were addressed prior to reaching the conclusions that are now being promoted.

\section{Issues addressed}

The Electronic Theses project aimed to achieve a wide range of objectives. Key to the project was the identification of examples of best practice of e-theses production, management and use. The project team was confident that much could be learned from the research and development work that had been undertaken already in countries such as the USA, Canada, Australia and Germany. Where possible, the team wished to avoid developing new solutions where good practice in operation in other countries could simply be adopted or adapted for use within the UK information environment.

The project team devoted a significant amount of time to ICT issues. Potentially useful, newly developed software was evaluated and assessed for suitability as the basis of an e-theses repository. Account was taken of related development work at the University of Edinburgh (described below) which aimed to enhance the functionality of specific e-theses software. Metadata requirements were considered. So, too, were the equipment and training needs of students who wish to submit theses that contain non-print media.

Administrative issues (such as the workflow pattern and institutional regulations) were considered in the course of the project and legal issues, such as intellectual property rights (IPR), were addressed. Efforts were made to identify the approaches that could be taken in order to achieve a 'culture change' within an institution. In particular, consideration was given to the identification of the most effective ways of undertaking advocacy work and the most efficient means of accumulating an adequate quantity of content for an e-theses repository.

In addition to examining issues of specific relevance to institutional e-theses collections, the project team assessed the advantages and disadvantages of establishing a national e-theses hub based on a federal, distributed or centralised model. The need for access to e-theses collections in perpetuity made it necessary to consider sustainability and the long term commitment of institutions to providing the human and technical resources necessary to support an e-theses repository. As with all forms of electronically stored information, and 
digital collections, account had to be taken of preservation and potential migration requirements.

Details of the Electronic Theses project, which ran from 2002-2004, and recommendations in the form of guidance notes, are available on the project Web site (http://www.rgu.ac.uk/library/e-theses.htm), the homepage of which is shown in Figure 1.

Figure 1. Homepage of the Electronic Theses project

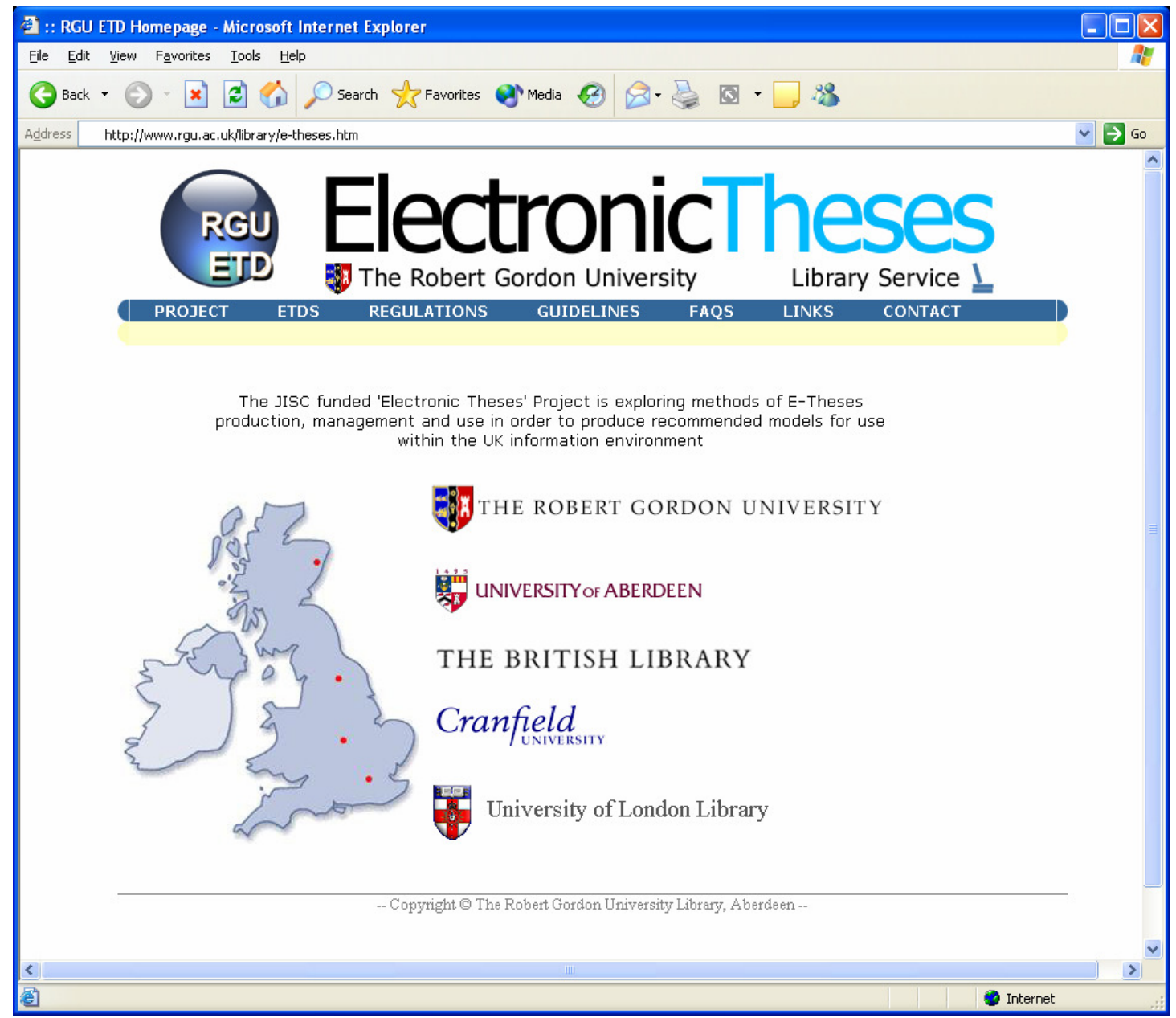

\section{Methodology}

To gain an overview of activities relating to electronic theses and dissertations (ETDs) internationally, the Web sites of every member of the Networked Digital Library of Theses and Dissertations (NDLTD) were examined (http://www.ndltd.org/). The results of this study of approximately 200 sites revealed that only a small percentage of the NDLTD institutions were dealing with a large quantity of e-theses in 2002. However, the Web pages from universities such as Virginia Tech (http://scholar.lib.vt.edu/theses/) yielded much valuable information. 
Staff from Virginia Tech had been pioneers in ETDs and were involved in the development of the NDLTD. Details were provided about the e-theses production process, software and equipment requirements, security, copyright and administrative issues. Some institutions provide statistics of use, which can prove invaluable when undertaking advocacy work, and some identify the training needs of students who wish to submit their thesis in electronic format.

To ensure that ongoing work relating to e-theses developments in the UK was taken into consideration, a brief questionnaire on the subject was circulated on the Society of College, National and University Libraries (SCONUL) mailing list (lis-SCONUL) at an early stage in the project. Twenty seven HE institutions responded to the questionnaire. Of these, five had a pilot project in operation to develop a system for the production and management of e-theses. The remainder had undertaken no such work in the area. However, of the 22 institutions without an e-theses collection, 16 replied that they would consider establishing a system if a suitable national model and guidelines were provided. Four more stated that they would 'possibly' pursue such an activity. Of the remaining two, one indicated that the decision would be made by the registry due to the collegiate nature of the institution. The one response from a representative from an HE college that did not have university status stated that there was little likelihood of that establishment engaging in such an undertaking in the near future.

The findings from the surveys indicated that many universities would make use of guidance notes relating to all aspects of e-theses production, management and use. The project team therefore decided to provide such information in the form of a series of Web pages. The resulting pages combine suggestions (e.g. with regard to workflow arrangements) and factual information (e.g. with regard to metadata). Some recommendations are based on the evidence of good practice elsewhere (e.g. the way in which to undertake effective advocacy work) and some are based on the results of practical testing (e.g. the selection of software).

The findings of the FAIR e-theses projects, as available by January 2004, were announced to approximately 60 delegates who attended a seminar on the subject at the ULL. Comments and feedback from the delegates led to further work and refinements to the project recommendations and guidance notes over the next eight months. Then, at a seminar held at the British Library in September 2004, the results of the projects were put forward as recommendations to the UK HE community at large.

\section{Results and recommendations}

\subsection{Infrastructure}


As a result of the Electronic Theses project team's investigations, the recommendation was made that there should be a hybrid approach to the provision of e-theses content. The establishment of institutional e-theses collections, preferably storing the e-theses alongside eprints as part of an institutional repository, was considered beneficial. This would allow institutions to keep their research output organised in a central collection and many could establish such a repository very quickly. It was appreciated that changes to the current practice in Wales (which involves the National Library of Wales holding copies of theses from the institutions that form part of the University of Wales) could require the establishment of a consortial e-theses repository. The project team acknowledged the concerns of smaller institutions that could not afford to establish and maintain their own e-theses collection, and the potential difficulties involved if they wish to establish local consortial arrangements. The team members also acknowledged general concerns about preservation and migration issues. Consequently, they proposed that a national collection should also be established.

The work of the British Library to date, with respect to the provision of theses, could form the basis of such an infrastructure which would support the deposit and management of theses throughout the HE sector. Such a national repository would encourage and enable access to the content of the theses by all potential users. In addition to acting as a central host, for institutions that wish to have their theses stored centrally, the British Library service could employ interfaces to harvest the necessary data and metadata for the online provision of theses that are stored in individual institutional or consortial repositories. A single search interface which allows all electronically stored theses to be viewed from one access point would be of great benefit to users. A national scheme provided by the British Library would need to take account of digital sustainability issues (i.e. preservation and migration requirements) and this factor might also encourage many institutions to make their theses available to the central host in addition to storing the content themselves.

Work towards the creation of such a national e-theses service took a step nearer to becoming reality towards the end of 2004 as the result of an Invitation to Tender for JISC funding for a UK HE e-theses Test-bed Project (http://www.jisc.ac.uk/index.cfm?name=funding etheses). The call for proposals "to undertake a test-bed implementation project to deliver an infrastructure to support the deposit, access and use of research theses for the UK Higher Education (HE) sector" was issued in September 2004. It acknowledged the outcomes of the FAIR Programme projects and associated promotion of the development of institutional repositories compliant with the Open Archives Initiative (OAI) standard for the storage of etheses locally. It acknowledged the need for further work in the areas of retrospective digitisation and rights management. Most significantly, it offered an opportunity to trial coordinated services, at a national level, in connection with e-theses deposit, access and use. 
In December 2004, JISC announced that the bid from a consortium led by the University of Glasgow had been successful and that funding would be made available for 18 months for the Electronic Theses Online Service (EThOS) project. The EThOS consortium includes many of the members of the three FAIR e-theses projects: the universities of Glasgow and Edinburgh, Cranfield University, The Robert Gordon University, and the British Library. The consortium also includes another JISC-funded initiative, the Securing a Hybrid Environment for Research Preservation and Access (SHERPA) consortium (represented by The University of Nottingham), as well as The National Library of Wales, and the universities of Birmingham, Warwick and Southampton. The EThOS project team aims to deliver a fully operational, easily scaleable and financially viable prototype UK e-theses online service and supporting infrastructure.

\subsection{Software}

\subsubsection{Software Selection}

One of the key objectives of the Electronic Theses project was the identification of suitable software packages with which a stand-alone e-theses repository could be created. The study of the work of the members of the NDLTD, at the beginning of the project in late 2002, provided the project team with a good understanding of the software and systems that other institutions were using and developing. At this time Virginia Tech's ETD-db was the most frequently used software for e-theses specific repositories, especially amongst east coast institutions within the US. However, significant software developments had taken place since the release of this software and several potential alternative solutions merited consideration. (A useful comparison of nine such repository systems has been produced by the Open Society Institute (Open Society Institute, 2004).)

To reach an agreement on the most suitable software for the project to recommend, it proved necessary to take into account a variety of key factors and criteria which, ideally, the software should satisfy.

\subsubsection{Availability and sustainability}

Given the diversity and potential expense of relevant software, the project team's preference was for an open source solution. This would spare libraries initial acquisition costs and it would allow institutions to modify the product to suit their particular needs. When assessing the available software, the team looked for evidence of the likelihood that the product would be developed over time and that there would be ongoing support for users. Demonstration of long-term commitment by the creators of the software provides a degree of reassurance that revisions and upgrades will continue. The existence of a dedicated, knowledgeable, and growing user community gives an indication that support will be available to those requiring assistance. 


\subsubsection{Interoperability}

In order to satisfy the needs of a distributed model of repositories within the UK, as opposed to a centralised service, issues of interoperability had to be carefully considered. To ensure that cross institutional access was achievable, it was clear that the software had to comply with the current version of the Open Archives Protocol for Metadata Harvesting (OAI-PMH): (http://www.openarchives.org/OAl/openarchivesprotocol.html). (Further information about this standard and the OAI can be found at: http://www.oaforum.org/tutorial/.)

\subsubsection{Suitability}

The project team considered it essential that the proposed software would work across a wide variety of operating systems and hardware types. The basic requirement was for the software to provide an intuitive and efficient user interface. This would ensure that administrators would be able to use the system and that students and other users would not be put off by an overly complicated, or overly simplistic, system.

Another important factor which was taken into consideration was the existence of potentially relevant software already in use in UK institutions. The EPrints software, developed at the University of Southampton, is one such product (http://software.eprints.org/). This package benefits from having a well established user base amongst institutions with e-prints collections. The software meets the criteria listed above, and it is highly suitable for use as an e-theses repository. Institutions that already have the software installed should find it a simple task to incorporate e-theses into their existing system. Unnecessary work involved in running dual systems can be avoided and server space is saved.

Increasing amounts of publicity about another potentially useful piece of software led the project team to investigate the suitability of DSpace and, ultimately, to recommend it as a good alternative to EPrints (http://www.dspace.org/). DSpace was developed jointly by the Massachusetts Institute of Technology (MIT) and the Hewlett-Packard company. DSpace is slightly newer in design than EPrints and utilises a different set of pre-requisite software but, in terms of core functionality, there is broad similarity. (A brief overview of the two packages is provided in the following sections.)

Further information on this subject, including comparisons between software packages that could be used for e-theses repositories, can be found in recent articles by Jones (2004) and Nixon (2003). These papers are written by representatives of the University of Edinburgh's Theses Alive! project and the University of 'Glasgow's DAEDALUS projects respectively. The three JISC funded e-theses projects worked independently with regard to the assessment of potentially suitable software and it is reassuring for the HE community at large that their findings and recommendations have much in common. 


\subsubsection{DSpace}

At present RGU is running version 1.1.1 of the DSpace software, however, it will be upgrading to 1.2.1 during 2005. The Electronic Theses project group visited MIT in June 2004 and met staff who are involved with DSpace developments to discuss a variety of issues such as workflows and implementation/integration. A demonstration of the new version of DSpace software was provided by MIT and it highlighted a variety of useful additions and improvements to the functionality of the system for both the users and administrators. New features include full-text extraction and content searching for Word, PDF, HTML and text documents. The ability to add thumbnail images for graphics files was a welcome addition and will hopefully be the beginning of further such features that will encourage and support the inclusion of a wide range of multimedia files and objects. A number of significant changes to the administration section of the software allow more detailed and efficient customisation of the system and a more user-friendly and intuitive interface design.

With this latest DSpace release, the new RGU installation will also be augmented by the addition of the latest version (0.4 Beta 1) of Edinburgh University's Theses Alive Plug-in for Institutional Repositories (Tapir) add-on. The Tapir will help tailor the repository for the submission of e-theses, incorporating the UK Metadata core set described below (http://www.rgu.ac.uk/library/guidelines/metadata.html).

\subsubsection{EPrints}

Work with EPrints software at RGU is also continuing, with a similar fresh installation of the latest release (version - 2.3.7.1), to be in place during 2005. The EPrints Web site lists improvements to the current update in the following areas:

- default configuration (with detailed help);

- full-text searching;

- searching for names and dates;

- RSS (Really Simple Syndication) output;

- user interface;

- views e.g. to enable make sub-views. e.g. /view/type_and_year/article/2000/);

- support for Apache 2.0 and Perl 5.8.1;

- automatic content negotiation for multilingual sites.

The EThOS project team hopes to develop an e-theses specific add-on for the EPrints platform similar to the Tapir add-on for DSpace during the course of its work. Once the 
project Web site is available, information on relevant developments will be provided and feedback from users of the software will be welcome.

\subsection{Metadata}

As part of the Electronic Theses project's work to develop a model which UK HE institutions could adopt, the use of metadata to describe the content of e-theses was investigated. It was considered important to recommend a standard set of metadata elements to describe the content of e-theses repositories. The intention was not to specify a restrictive set from which institutions could not deviate, but rather to provide a core set of descriptors which institutions could use as a basis (adding their own descriptors if they so wish). Such a core set should fit with any national e-theses repository that may be established within the UK, and the core set for e-theses collections should be a 'good fit' with the metadata within more extensive research repositories established by individual institutions.

With due regard to work done by the Theses Alive! project at the University of Edinburgh, the Dublin Core element set was examined for elements that would be appropriate for describing theses, and comparisons were made with other schemas such as ETD-MS and the Theses and Dissertation Mark-up DTD. In order to allow for maximum interoperability with other repositories and with other non-ETD materials within the same repository, it was considered preferable to use standard Dublin Core elements wherever possible. Through discussions between representatives from the Electronic Theses, Theses Alive! and DAEDALUS projects, and representatives from the British Library, an initial draft of core elements was formulated.

This initial draft was discussed with members of other research projects in the JISC FAIR Programme who are involved in work associated with the development of institutional repositories. The draft was presented at the seminar at the ULL in January 2004 and feedback on the proposal was encouraged. (The recommendations published by the EPrints UK project regarding cataloguing guidelines and the use of metadata were also checked in order to ensure compatibility.)

The resulting metadata set, as shown in Table I, which is recommended for use by UK institutions in their e-theses repositories, has been integrated into the Tapir submission system that the Theses Alive project has developed for use with DSpace ETD repositories. The question of who provides the information will depend upon the submission process that the institution adopts. A cataloguer may populate all the required fields. However, if a selfsubmission process is adopted and students populate some of the fields themselves, the information can be checked and verified by a member of staff later. 
Table I UK ETD Metadata Core Set

\begin{tabular}{|c|c|c|c|}
\hline Field Name & Comments & $\begin{array}{l}\text { QDC } \\
\text { Element.Qualifier }\end{array}$ & $\begin{array}{l}\text { Populated } \\
\text { By }\end{array}$ \\
\hline Title & $\begin{array}{l}\text { Full title, including any } \\
\text { subtitle }\end{array}$ & title & student \\
\hline Alternative Title & $\begin{array}{l}\text { Other titles for the work, } \\
\text { e.g. Translations or } \\
\text { abbreviations. }\end{array}$ & $\begin{array}{l}\text { title.alternative } \\
\text { (refinement) }\end{array}$ & student \\
\hline Author & $\begin{array}{l}\text { The author of the work as } \\
\text { on the title page. Separate } \\
\text { the surname (or family } \\
\text { name) from the forenames, } \\
\text { given names or initials with } \\
\text { a comma. e.g. Smith, } \\
\text { Andrew J. }\end{array}$ & creator & student \\
\hline $\begin{array}{l}\text { Supervisor(s) } \\
\text { /advisor }\end{array}$ & $\begin{array}{l}\text { Thesis supervisor, other } \\
\text { supervisors, and advisors. } \\
\text { Format as for author. }\end{array}$ & $\begin{array}{l}\text { contributor.advisor } \\
\text { (refinement) }\end{array}$ & student \\
\hline $\begin{array}{l}\text { Subject } \\
\text { keywords }\end{array}$ & $\begin{array}{l}\text { Any keywords that the } \\
\text { student or librarian feel } \\
\text { belong in the metadata. } \\
\text { Populated by student for } \\
\text { free text and librarian to } \\
\text { verify and add full subject } \\
\text { headings based on DDC, } \\
\text { LCSH etc. as below. }\end{array}$ & subject & $\begin{array}{l}\text { student / } \\
\text { institutional } \\
\text { librarian to } \\
\text { verify }\end{array}$ \\
\hline Abstract & $\begin{array}{l}\text { Include translations in } \\
\text { "repeatable" section. }\end{array}$ & $\begin{array}{l}\text { description.abstract } \\
\text { (refinement) }\end{array}$ & student \\
\hline DDC & $\begin{array}{l}\text { Dewey Decimal } \\
\text { Classification headings as } \\
\text { assigned by librarian. }\end{array}$ & $\begin{array}{l}\text { subject.DDC } \\
\text { (encoding scheme) }\end{array}$ & $\begin{array}{l}\text { institutional } \\
\text { librarian }\end{array}$ \\
\hline LCC & $\begin{array}{l}\text { Library of Congress } \\
\text { Classification headings as } \\
\text { assigned by librarian. }\end{array}$ & $\begin{array}{l}\text { subject.LCC } \\
\text { (encoding scheme) }\end{array}$ & $\begin{array}{l}\text { institutional } \\
\text { librarian }\end{array}$ \\
\hline LCSH & $\begin{array}{l}\text { Library of Congress Subject } \\
\text { Headings as assigned by } \\
\text { librarian. }\end{array}$ & $\begin{array}{l}\text { subject.LCSH } \\
\text { (encoding scheme) }\end{array}$ & $\begin{array}{l}\text { institutional } \\
\text { librarian }\end{array}$ \\
\hline MESH & $\begin{array}{l}\text { Medical Subject Headings } \\
\text { as assigned by librarian. }\end{array}$ & $\begin{array}{l}\text { subject.MESH } \\
\text { (encoding scheme) }\end{array}$ & $\begin{array}{l}\text { institutional } \\
\text { librarian }\end{array}$ \\
\hline UDC & $\begin{array}{l}\text { Universal Decimal } \\
\text { Classification headings as } \\
\text { assigned by librarian. }\end{array}$ & $\begin{array}{l}\text { subject.UDC } \\
\text { (encoding scheme) }\end{array}$ & $\begin{array}{l}\text { institutional } \\
\text { librarian }\end{array}$ \\
\hline $\begin{array}{l}\text { Institution. } \\
\text { College. } \\
\text { Department }\end{array}$ & $\begin{array}{l}\text { Name of institution } \\
\text { awarding degree; name of } \\
\text { college; name of } \\
\text { department, school or } \\
\text { centre. (Separated with full } \\
\text { stops: e.g. The Robert } \\
\text { Gordon University. Faculty } \\
\text { of Design and Technology. }\end{array}$ & publisher & $\begin{array}{l}\text { default } \\
\text { maintained } \\
\text { by institution }\end{array}$ \\
\hline
\end{tabular}




\begin{tabular}{|c|c|c|c|}
\hline & School of Computing). & & \\
\hline Sponsors & Sponsor of student. & $\begin{array}{l}\text { contributor.sponsor } \\
\text { (refinement) }\end{array}$ & student \\
\hline $\begin{array}{l}\text { Type. } \\
\text { Qualification } \\
\text { level. } \\
\text { Qualification } \\
\text { name }\end{array}$ & 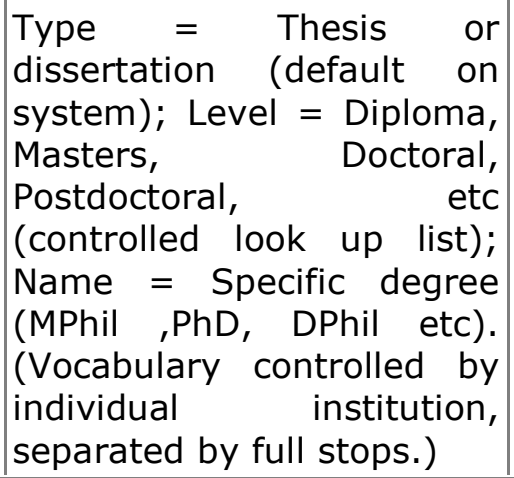 & type & student \\
\hline Language & 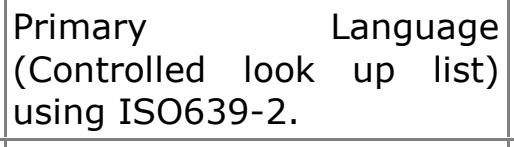 & $\begin{array}{l}\text { language.ISO639-2 } \\
\text { (encoding scheme) }\end{array}$ & student \\
\hline Date of Award & $\begin{array}{l}\text { Date degree } \\
\text { format: } \\
\text { (ISO8601). }\end{array}$ & $\begin{array}{l}\text { date.issued } \\
\text { (refinement) }\end{array}$ & \begin{tabular}{|l} 
student, \\
institutional \\
librarian to \\
verify
\end{tabular} \\
\hline Citations & $\begin{array}{l}\text { Citations to previously } \\
\text { published sections of this } \\
\text { thesis. Applies particularly } \\
\text { to "thesis by publication". } \\
\text { Possible problem enforcing } \\
\text { any citation standard. }\end{array}$ & $\begin{array}{l}\text { relation.hasVersion } \\
\text { (refinement) }\end{array}$ & student \\
\hline $\begin{array}{l}\text { Included/Quoted } \\
\text { work }\end{array}$ & References to other works. & $\begin{array}{l}\text { relation.references } \\
\text { (refinement) }\end{array}$ & student \\
\hline Rights & $\begin{array}{l}\text { e.g. Copyright/IPR } \\
\text { statement regarding rights } \\
\text { management, or URI of } \\
\text { Creative Commons licence. } \\
\text { Possibility of a change in } \\
\text { rights agreement after a } \\
\text { specified time. }\end{array}$ & rights & $\begin{array}{l}\text { institutional } \\
\text { librarian }\end{array}$ \\
\hline Identifier & ID for the object(s). & $\begin{array}{l}\text { identifer.URL } \\
\text { (encoding scheme) }\end{array}$ & $\begin{array}{l}\text { system, } \\
\text { student can } \\
\text { optionally } \\
\text { add IDs for } \\
\text { alternative } \\
\text { locations }\end{array}$ \\
\hline File Format & $\begin{array}{l}\text { File type for preservation } \\
\text { information (for each of } \\
\text { these there may be } \\
\text { multiple files). }\end{array}$ & $\begin{array}{l}\text { format.IMT } \\
\text { (encoding scheme) }\end{array}$ & system \\
\hline File Size & $\begin{array}{l}\text { Size of file for preservation } \\
\text { information and integrity } \\
\text { checking (For each of these } \\
\text { there may be multiple } \\
\text { files). }\end{array}$ & $\begin{array}{l}\text { format.extent } \\
\text { (refinement) }\end{array}$ & system \\
\hline
\end{tabular}




\subsection{Legal and cultural issues}

Copyright and Intellectual Property Rights (IPR) are a source of concern for those establishing e-theses repositories and for those providing the content. The use of third-party copyright material, embedded within a thesis, may be a particular problem. However two recent developments have had a significant bearing on the approach adopted by advocates of e-theses.

The first development relates to the increased availability of advice. The publication of a JISC Legal Information Service briefing paper (Andrew, 2004) on intellectual property and e-theses provides useful guidelines and has been widely welcomed by the HE community. The paper considers the main issues involved when converting paper-based theses into digital format. It provides information about the ownership of copyright within theses, it examines the rights and responsibilities of authors, institutions, end users, and other third parties, and it provides a number of sample licence agreements. An appendix to the paper contains a useful flowchart which highlights the legal issues that need to be addressed when publishing etheses.

The second development, which affects the way in which legal matters associated with etheses are addressed, reflects a general culture change. Comments from academic staff within The Robert Gordon University and comments from delegates at the project seminars in 2004, along with discussions with a representative from the UK Council for Graduate Education (UKCGE), reveal a change in attitude towards the need for students to understand IPR issues. Previously copyright was often considered 'a problem' and a factor that might deter students from submitting their work for presentation on the Web. However, with a stronger emphasis recently on training for new researchers, the requirement to produce etheses in a style fit for publication is now thought to provide an opportunity for students to learn about relevant legal rights and responsibilities. The need for students to enhance their ICT skills in order to produce an e-thesis was originally considered a burden but it is now seen to be advantageous. Similarly, the need for students to have a better understanding of copyright and IPR matters when preparing their research results for publication on the Web is gradually being accepted as a positive development. The key skills gained are likely to benefit students in their future careers.

During the course of discussions with research supervisors, some expressed concern about the increased likelihood of plagiarism taking place if theses are freely available on the Web. Easy access to the full text of e-theses may tempt some students to consider using such material inappropriately. However, the key point with regard to plagiarism of the content of etheses is that it is easier to detect instances where this activity has taken place when the 
material is published on the Web. Electronic detection software is available, and further information on this subject can be obtained from the relevant JISC Web page (http://www.jisc.ac.uk/index.cfm?name=plagiarism detection ).

\subsection{Administration}

Various administrative issues have to be tackled when establishing an e-theses repository. Consideration has to be given to the workflow, and resources have to be made available to support the process. An example workflow chart, from Cranfield University, is available on the Electronic Theses project Web site. However, each institution will have its own requirements and the Cranfield model will have to be adapted to meet specific needs.

An assessment of the workflow process should provide institutions with an indication of the resources they need to establish and populate an e-theses repository. The resources involved may include ICT equipment (such as a server) and will include staff time (for installing and upgrading software, for advocacy work, and for assigning metadata etc). A business case may need to be made in order to obtain the necessary funding.

Research Committees may also have to be approached to endorse changes to institutional policies and procedures. In particular, as the example regulations on the Electronic Theses project Web pages indicate, advice on the submission process may need to be updated to accommodate e-theses. Similarly, forms completed by students when they deposit a copy of their thesis in the library will need to be changed to include agreement about the publication of the work on the Web.

All of the above activities are likely to involve lengthy discussions with senior managers and relevant committee members. It is therefore essential that negotiations begin early and that advocacy work is targeted appropriately.

\subsection{Advocacy}

A key finding of the Electronic Theses project team was the need to target advocacy work since different market groups within institutions have different concerns and priorities. Four key groups were identified.

\subsubsection{Students}

Students provide the content for e-theses repositories. They are also users of the e-theses that are available. Improved access to the work of others is helpful, but the key benefits for 
students relate to the promotion of their own work. The opportunity to present their research findings in electronic format allows students to express their results in more flexible and creative ways. Moreover, statistics, for example from Virginia Tech, indicate that theses are likely to be read more widely if they are easily accessible on the Web.

\subsubsection{Academic Staff}

Researchers are most interested in obtaining relevant information quickly. The ability to access remote material immediately, 24 hours a day, and regardless of use by other readers has a major appeal. The availability of the full text of theses reduces the need to request interlibrary loans on the basis of brief abstracts.

\subsubsection{Senior management}

Key administrators and managers within universities are particularly keen to see the research output of staff and students widely disseminated and publicised. Increased use of the institution's theses is likely to lead to increased citations and, subsequently, an improved research profile within the HE community.

\subsubsection{Librarians}

Of most importance to library staff is the opportunity to improve the service they provide to users and to raise levels of customer satisfaction accordingly. However, the establishment of an e-theses repository, and the means of accessing e-theses via the Internet, leads to other benefits, notably savings in staff time spent retrieving and re-shelving hard-copy theses and obtaining interlibrary loans. Storage space is saved and the collection of usage statistics is easier.

\section{Conclusion}

The increasing amount of interest in the establishment of digital repositories in general, and etheses collections in particular, indicates that a turning point has been reached. For several years attempts have been made to test methods of e-theses production and to consider how access to full text ETDs could be arranged. The publication of the findings of the relevant JISC funded FAIR Programme projects have now provided the HE community with sufficient guidelines to begin establishing their own institutional e-theses collections. Funding from JISC is allowing the EThOS project team to create and test a national infrastructure for the storage, management and provision of e-theses. Advocacy work is now needed to produce a critical mass of content for the emerging e-theses repositories. 


\section{References}

Andrew, T. (2004), Intellectual property and electronic theses, JISC Legal Information Service. Available at: http://www.jisclegal.ac.uk/publications/ethesesandrew.htm (accessed: 22 April 2005)

Jones, R. (2004), "DSpace vs. ETD-db: choosing software to manage electronic theses and dissertations", Ariadne, Issue 38. Available at http://www.ariadne.ac.uk/issue38/jones/ (accessed: 22 April 2005)

Nixon, W. (2003), "DAEDALUS: initial experiences with EPrints and DSpace at the University of Glasgow", Ariadne, Issue 37. Available at http://www.ariadne.ac.uk/issue37/nixon/ (accessed: 22 April 2005)

Open Society Institute (2004), A guide to institutional repository software, Open Society Institute, $3^{\text {rd }}$ ed. Available at http://www.soros.org/openaccess/software/ (accessed: 22 April 2005)

Roberts, A. (1997), Survey on the use of doctoral theses in British universities, (British Library Research and Innovation Report 57), Edinburgh University Library, Edinburgh. Available at: http://www.lib.ed.ac.uk/Theses/ (accessed: 22 April 2005) 